\title{
Intravenous epoprostenol improves oxygenation index in patients with persistent pulmonary hypertension of the newborn refractory to nitric oxide
}

\author{
Kaashif Aqeeb Ahmad ${ }^{1,2} \cdot$ Jesse Banales ${ }^{2} \cdot$ Cody Lance Henderson $^{1,2} \cdot$ Susanne Erika Ramos $^{1} \cdot$ \\ Katherine Marie Brandt ${ }^{1,2} \cdot$ George Charles Powers ${ }^{1,2}$
}

Received: 1 April 2018 / Revised: 19 June 2018 / Accepted: 26 June 2018 / Published online: 25 July 2018

(c) Springer Nature America, Inc. 2018

\begin{abstract}
Objectives Evaluate the short-term effects of IV epoprostenol in neonates with persistent pulmonary hypertension (PPHN) of the newborn.

Study Design We reviewed 36 patients with inhaled nitric oxide (iNO) refractory PPHN placed on IV epoprostenol from 2010 to 2015. Patients were categorized as responders or non-responders (who either died or required extracorporeal membranous oxygenation).

Results There were 15 responders and 21 non-responders. Pulmonary hypoplasia was the etiology of PPHN for $57 \%$ of nonresponders vs. $13 \%$ of responders. Median oxygenation index (OI) was similar at baseline (41.8 non-responders vs. 36.5 responders, $p=0.41)$ with responders having a significantly lower OI by $4 \mathrm{~h}$ of treatment $(42.3$ vs. $23.1, p=0.002)$. Epoprostenol responders had a median OI decrease of 11.6 within $4 \mathrm{~h}(p=0.017)$ with a significant response persisting through $24 \mathrm{~h}$.

Conclusion In infants with iNO-refractory PPHN, initiation of IV epoprostenol was associated with a significant and rapid OI reduction among responders.
\end{abstract}

\section{Background}

The estimated incidence of persistent pulmonary hypertension (PPHN) of the newborn in term and near-term newborns is 2 per 1000 live births [1]. PPHN has a variety of etiologies, most commonly meconium aspiration syndrome, congenital diaphragmatic hernia, and sepsis. In term infants, controlled trials have proven the benefit of inhaled nitric oxide (iNO) as a replacement for deficient endogenous NO, leading to now standard use of iNO for PPHN $[1,2]$. While the safety and efficacy of iNO are well studied and known to decrease the need for extracorporeal membranous oxygenation (ECMO) in term and near-term neonates with PPHN, the mortality and length of hospital stay after rescue

Kaashif Aqeeb Ahmad

kaashif.ahmad@bcm.edu

Pediatrix Medical Group, San Antonio, TX, USA

2 Department of Pediatrics, Baylor College of Medicine, San Antonio, TX, USA
iNO have remained unchanged [3]. Earlier use of iNO may potentially offer greater benefit in this regard [4].

Other treatment modalities have shown promise in the treatment of pulmonary hypertension in children and adults. These include the use of prostanoids, phosphodiesterase inhibitors, and endothelin blockade. Epoprostenol is a synthetic analog of prostacyclin, a naturally occurring prostanoid in the body produced via arachidonic acid metabolism. Epoprostenol stimulates the production of cyclic adenosine monophosphate (cAMP)-mediated vasodilation and as a result, pulmonary and systemic vasodilation occur. Epoprostenol is FDA approved for the treatment of pulmonary hypertension in adults. However, epoprostenol's short half-life of 3-5 min necessitates continuous delivery, either intravenously, inhaled, or subcutaneously [5].

In neonates, limited data exist regarding the efficacy of epoprostenol for the treatment of PPHN. Case reports and small case series have demonstrated beneficial effects of intravenous (IV) or inhaled epoprostenol when treating neonates with PPHN [6-12]. Studies demonstrating beneficial treatment effects of epoprostenol in older children 
$[10,13-21]$ have also indicated that further studies in both populations may be warranted.

Since 2010, we have utilized IV epoprostenol as an adjunct to standard therapy in treating PPHN for those patients with continued significant elevation of oxygenation index (OI) after initiation of iNO therapy. The purpose of this study was to retrospectively review our experience of the use and efficacy of epoprostenol in ECMO eligible neonates with iNO-refractory PPHN, specifically evaluating for tolerance and early clinical response. Based on our experience, we hypothesized that IV epoprostenol led to rapid reduction in the OI for exposed infants with controllable adverse effects.

\section{Methods}

\section{Setting}

CHRISTUS Santa Rosa Children's Hospital (established 1959) became a free-standing children's hospital in 2012 and is now named The Children's Hospital of San Antonio. All described patients were admitted to the neonatal intensive care unit (NICU) between 2010 and 2015. IRB approval was obtained from the CHRISTUS Health IRB.

\section{Patients}

Since 2010, neonates admitted to The Children's Hospital of San Antonio NICU have been considered eligible for IV epoprostenol if they received a diagnosis of hypoxemic respiratory failure secondary to PPHN and continued to have an OI greater than 25 after initiation of standard therapies. During the study period our standard local therapy for severe PPHN included iNO, high-frequency mechanical ventilation with maximal supplemented oxygen, IV sedation (typically fentanyl and midazolam) and IV milrinone.

We retrospectively collected data for patients with iNOrefractory pulmonary hypertension who received IV epoprostenol after admission to our institution and met criteria for ECMO consideration. We therefore excluded those infants $<1800$ g, <34 weeks' gestation, with complex congenital cardiac disease, who had epoprostenol administered after initiation of ECMO, or who had inadequate data available from the medical record. We had no contemporary control group available. As a result, study patients were divided into two groups-'Non-responders' and 'Responders'. We defined non-responders as any patient who ultimately required ECMO and/or died prior to discharge, regardless of clinical response to epoprostenol. We defined responders as all other patients.

Data were hand collected into case report forms and entered into SPSS v24. Tables were generated for baseline data, medication exposures, and clinical outcomes. Blood gas data along with correlating ventilator settings were obtained from $6 \mathrm{~h}$ prior to IV epoprostenol initiation until $24 \mathrm{~h}$ post-initiation, death, or placement on ECMOwhichever came first. OI was calculated at baseline (last blood gas within $2 \mathrm{~h}$ prior to initiation of epoprostenol) and at 4-h intervals through the $24-\mathrm{h}$ period after initiation. As our grouping into 'Responders' and 'Non-Responders' was largely based on need for ECMO, we focused on the initial 24-h period as the critical window during which the clinical decision regarding ECMO placement is made. No patients were placed onto ECMO more than 24-h after epoprostenol initiation.

\section{Epoprostenol administration}

Although a strict protocol did not exist for epoprostenol dose at initiation, institutional standard practice for epoprostenol was to begin infusion at $4 \mathrm{ng} / \mathrm{kg} / \mathrm{min}$ as a continuous infusion through a dedicated IV or lumen. Epoprostenol infusions were increased in increments of $2 \mathrm{ng} / \mathrm{kg} / \mathrm{min}$ until either a clinically significant reduction in OI was seen by the attending clinician, adverse effects such as worsening hypotension limited further increases, or a pre-defined maximal dose of $20 \mathrm{ng} / \mathrm{kg} / \mathrm{min}$ was reached. We did not predefine a threshold for hypotension or other adverse effects mandating cessation of epoprostenol. Individual clinicians made determinations regarding need to halt epoprostenol and these were counted if explicitly documented by the clinician.

\section{Analysis}

$\chi^{2}$, Fischer's exact test, or the Mann-Whitney $U$ test were used to compare demographic data, blood gas data, and outcome variables between the groups. Changes in OI over time were compared utilizing Friedman testing for all time points and the Wilcoxon signed-rank test to compare baseline OI to later time points. Significance was defined as $p<0.05$.

\section{Results}

A total of 36 patients were included in the study, 21 in the non-responder group and 15 in the responder group. Of non-responders, $14(66.7 \%)$ were placed on ECMO and 14 $(66.7 \%)$ died. Seven of the patients who died did not receive ECMO therapy. These seven patients had anomalies or comorbidities for which the healthcare team and/or families ultimately felt ECMO would not be beneficial. Those diagnoses included four with congenital diaphragmatic hernia $(\mathrm{CDH})$, two of whom had additional anomalies (omphalocele and polycystic kidney disease), and three 
Table 1 Maternal and delivery information

\begin{tabular}{|c|c|c|c|}
\hline & $\begin{array}{l}\text { Non- } \\
\text { responders } \\
n=21\end{array}$ & $\begin{array}{l}\text { Responders } \\
n=15\end{array}$ & $p$-Value \\
\hline $\begin{array}{l}\text { Prenatal care received } \\
(\%)\end{array}$ & $18(85.7 \%)$ & $14(93.3 \%)$ & 0.63 \\
\hline Vaginal delivery $(\%)$ & $10(47.6)$ & $6(40)$ & 0.74 \\
\hline Male gender $(\%)$ & $11(52.4)$ & $9(60)$ & 0.74 \\
\hline Maternal race & & & 0.6 \\
\hline White & $4(19)$ & $2(13.3)$ & \\
\hline Black & $1(4.8)$ & $1(6.7)$ & \\
\hline Hispanic & $14(66.7)$ & $12(80)$ & \\
\hline Not documented & $2(9.5)$ & 0 & \\
\hline $\begin{array}{l}\text { Prolonged rupture of } \\
\text { membranes }(\%)\end{array}$ & $1(4.8)$ & $2(13.3)$ & 0.56 \\
\hline Oligohydraminos (\%) & $2(9.5)$ & $2(13.3)$ & 1 \\
\hline Polyhydraminos (\%) & $1(4.8)$ & 0 & 1 \\
\hline Fetal hydrops (\%) & 0 & 0 & - \\
\hline $\begin{array}{l}\text { Gestational age (median } \\
\text { weeks, IQR) }\end{array}$ & $38(36,40)$ & $39(37,40)$ & 0.49 \\
\hline $\begin{array}{l}\text { Birth weight (median, } \\
\text { IQR) }\end{array}$ & $\begin{array}{l}2970(2575, \\
3277)\end{array}$ & $\begin{array}{l}3202(3000, \\
3690)\end{array}$ & 0.09 \\
\hline $\begin{array}{l}\text { Apgar } 1 \text { min (median, } \\
\text { IQR) }\end{array}$ & $3(1,7)$ & $3(2,6)$ & 0.54 \\
\hline $\begin{array}{l}\text { Apgar } 5 \text { min (median, } \\
\text { IQR) }\end{array}$ & $5(3,8)$ & $7(5,8)$ & 0.4 \\
\hline $\begin{array}{l}\text { Meconium at delivery } \\
(\%)\end{array}$ & $7(33.3)$ & $10(66.7)$ & 0.09 \\
\hline
\end{tabular}

patients with severe pulmonary hypoplasia (two secondary to polycystic kidney disease and one with urethral obstruction and oligohydramnios). No significant differences were noted among baseline demographic and delivery information (Table 1).

Patients within the non-responder group had epoprostenol initiated at an earlier age and received higher doses of dopamine 12-24 h post-epoprostenol initiation (Table 2). No significant differences were noted in use of milrinone or corticosteroids. All patients had iNO initiated prior to epoprostenol. Of 24 patients that had an exact time of iNO initiation documented, median duration between iNO and epoprostenol initiation was $7 \mathrm{~h}$ with an interquartile range of 4-21.4 h. Patients did not have iNO weaned during the first 24-h on epoprostenol.

Non-responders overall had a significantly higher likelihood of diagnosis with congenital diaphragmatic hernia or other forms of pulmonary hypoplasia whereas the responder group had meconium aspiration syndrome and infectious etiologies as the most common underlying diagnoses for pulmonary hypertension (Table 3 ). We noted a more frequent need for IV fluid resuscitation in the $24 \mathrm{~h}$ after epoprostenol initiation in the non-responder group but no significant difference in the rate of patients with hypotension significant enough to require cessation of the epoprostenol infusion (Table 3). Overall, 22\% of the cohort had their epoprostenol infusion halted by the clinician due to documented concern regarding epoprostenol induced hypotension.

Responders and non-responders did not have significantly different OIs at baseline. Comparing the OI of responders and non-responders at all time points after epoprostenol initiation found a significantly lower OI for responders through 20-h (Table 4). We conducted Friedman testing for those patients who had blood gas data available at baseline and all six subsequent time points. However, this included only 7 of 21 non-responders and 11 of 15 responders. For these patients, we did not find a statistically significant change in OI among non-responders $(p=0.63)$ or responders $(p=0.1)$. As all study patients had baseline OI values available, we proceeded to compare matched samples of baseline OI values with later time points for both responder and non-responder groups utilizing the Wilcoxon signed-rank test. Compared to baseline, the non-responder group had no significant changes in OI at six later time points through $24 \mathrm{~h}$ post-initiation. Epoprostenol responders had a significant decrease in OI by $4 \mathrm{~h}$ and maintained this effect at all later time points. (Table 4).

\section{Discussion}

This report of 36 patients represents the largest published cohort of neonates with pulmonary hypertension to be treated with IV epoprostenol for iNO-refractory PPHN. This critically ill group of patients had a median OI of 41.8 among non-responders and 35.6 among responders prior to epoprostenol therapy, both groups at high risk of mortality. In this cohort, we identified a subset of infants who appeared to have a rapid decline in OI following initiation of IV epoprostenol. This occurred within $4 \mathrm{~h}$ of epoprostenol initiation with a sustained response through $24 \mathrm{~h}$ of exposure.

Eleven of 15 IV epoprostenol responders had meconium aspiration syndrome or an infectious etiology for their pulmonary hypertension. These diagnoses would be expected to have reversible pathology for their PPHN with intact pulmonary vascular beds and may be the area of greatest potential therapeutic focus for IV epoprostenol. In contrast, the majority of non-responders had pulmonary hypoplasia from a variety of causes. This finding is consistent with an earlier report finding no impact of epoprostenol on mortality for patients with $\mathrm{CDH}$ [22]. Given our epoprostenol institutional dosage limitation at $20 \mathrm{ng} / \mathrm{kg} / \mathrm{min}$, we cannot exclude that a response may have occurred at higher doses in these patients. 
Table 2 Medication exposures

\begin{tabular}{|c|c|c|c|}
\hline & $\begin{array}{l}\text { Non-responders } \\
n=21\end{array}$ & $\begin{array}{l}\text { Responders } \\
n=15\end{array}$ & $p$-Value \\
\hline \multicolumn{4}{|l|}{ Epoprostenol } \\
\hline Age at epoprostenol initiation (median hours, IQR) & $16.5(7.5,23.5)$ & $36(16,93)$ & 0.028 \\
\hline Initial epoprostenol dose (median $\mathrm{ng} / \mathrm{kg} / \mathrm{min}, \mathrm{IQR}$ ) & $4(4,6)$ & $4(3,4)$ & 0.14 \\
\hline $\begin{array}{l}\text { Maximum epoprostenol dose (median } \mathrm{ng} / \mathrm{kg} / \mathrm{min} \text {, } \\
\mathrm{IQR} \text { ) }\end{array}$ & $16(9,21)$ & $12(8,20)$ & 0.5 \\
\hline $\begin{array}{l}\text { Time to reach maximum epoprostenol dose } \\
\text { (median hours, IQR) }\end{array}$ & $11.5(3,55)$ & $20(12,46)$ & 0.96 \\
\hline \multicolumn{4}{|l|}{ Dopamine } \\
\hline $\begin{array}{l}\text { Dopamine exposure within } 24 \mathrm{~h} \text { of epoprostenol } \\
\text { initiation: }\end{array}$ & & & 0.94 \\
\hline Exposure for entire period & $12(57.1)$ & $10(66.7)$ & \\
\hline No exposure & $3(14.3)$ & $2(13.3)$ & \\
\hline $\begin{array}{l}\text { Dopamine in use at epoprostenol initiation then } \\
\text { stopped within } 24 \mathrm{~h}\end{array}$ & $2(9.5)$ & $1(6.7)$ & \\
\hline Dopamine initiated within $24 \mathrm{~h}$ after epoprostenol & $4(19)$ & $2(13.3)$ & \\
\hline $\begin{array}{l}\text { Dopamine dose at epoprostenol initiation } \\
(\mathrm{median} \mu \mathrm{g} / \mathrm{kg} / \mathrm{min}, \mathrm{IQR})\end{array}$ & $15(5,20)$ & $14(8,20)$ & 1 \\
\hline $\begin{array}{l}\text { Dopamine dose } 6 \mathrm{~h} \text { post-epoprostenol initiation } \\
\text { (median } \mu \mathrm{g} / \mathrm{kg} / \mathrm{min}, \mathrm{IQR})\end{array}$ & $15(9,20)$ & $12(9,20)$ & 0.42 \\
\hline $\begin{array}{l}\text { Dopamine dose } 12 \mathrm{~h} \text { post-epoprostenol initiation } \\
(\text { median } \mu \mathrm{g} / \mathrm{kg} / \mathrm{min}, \mathrm{IQR})\end{array}$ & $16(8,20)$ & $9.5(8,13)$ & 0.008 \\
\hline $\begin{array}{l}\text { Dopamine dose } 24 \mathrm{~h} \text { post-epoprostenol initiation } \\
(\mathrm{median} \mu \mathrm{g} / \mathrm{kg} / \mathrm{min}, \mathrm{IQR})\end{array}$ & $15(8,20)$ & $8(7,10)$ & 0.006 \\
\hline \multicolumn{4}{|l|}{ Epinephrine } \\
\hline $\begin{array}{l}\text { Epinephrine exposure within } 24 \mathrm{~h} \text { of epoprostenol } \\
\text { initiation }\end{array}$ & & & 0.051 \\
\hline Exposure for entire period & $6(28.6 \%)$ & $4(26.7 \%)$ & \\
\hline No exposure & $4(19)$ & $9(60)$ & \\
\hline $\begin{array}{l}\text { Epinephrine in use at epoprostenol initiation then } \\
\text { stopped within } 24 \mathrm{~h}\end{array}$ & $5(23.8)$ & $1(6.7)$ & \\
\hline Epinephrine initiated within $24 \mathrm{~h}$ after epoprostenol & $6(28.6 \%)$ & $1(6.7)$ & \\
\hline $\begin{array}{l}\text { Epinephrine dose at epoprostenol initiation } \\
\text { (median } \mu \mathrm{g} / \mathrm{kg} / \mathrm{min}, \mathrm{IQR} \text { ) }\end{array}$ & $0.08(0.05,0.1)$ & $0.1(0.075,0.25)$ & 0.28 \\
\hline $\begin{array}{l}\text { Epinephrine dose } 6 \mathrm{~h} \text { post-epoprostenol initiation } \\
\text { (median } \mu \mathrm{g} / \mathrm{kg} / \mathrm{min}, \mathrm{IQR})\end{array}$ & $0.15(0.08,0.45)$ & $0.15(0.1,0.35)$ & 1 \\
\hline $\begin{array}{l}\text { Epinephrine dose } 12 \mathrm{~h} \text { post-epoprostenol initiation } \\
\text { (median } \mu \mathrm{g} / \mathrm{kg} / \mathrm{min}, \mathrm{IQR})\end{array}$ & $0.15(0.05,0.35)$ & $0.13(0.11,0.2)$ & 1 \\
\hline $\begin{array}{l}\text { Epinephrine dose } 24 \mathrm{~h} \text { post-epoprostenol initiation } \\
\text { (median } \mu \mathrm{g} / \mathrm{kg} / \mathrm{min}, \mathrm{IQR})\end{array}$ & $0.2(0.12,0.38)$ & $0.12(0.1,0.23)$ & 0.62 \\
\hline Use of milrinone at epoprostenol initiation (\%) & $20(95.2)$ & $14(93.3)$ & 1 \\
\hline Use of dobutamine at epoprostenol initiation (\%) & $4(19)$ & 0 & 0.12 \\
\hline Use of vasopressin at epoprostenol initiation (\%) & $1(4.8)$ & 0 & 1 \\
\hline Use of norepinephrine at epoprostenol initiation (\%) & $1(4.8)$ & 0 & 1 \\
\hline Use of $\geq 2$ pressors at epoprostenol initiation & $12(57.1)$ & $11(73.3)$ & 0.49 \\
\hline
\end{tabular}

The use of milrinone, a phosphodiesterase- 3 inhibitor, for severe PPHN was routine practice at our institution throughout this study period. In this report, $94 \%$ of the cohort had initiation of IV milrinone prior to dosing with epoprostenol. However, based on available survey data [23,
24] milrinone utilization does not appear to have widespread adoption for use in PPHN. Limited animal and human data have found that milrinone may be beneficial in the setting of PPHN for those already receiving iNO therapy [25-28]. Clinical trials have been suggested to examine the 


\section{Primary diagnoses leading to pulmonary} hypertension

\begin{tabular}{|c|c|c|c|}
\hline Congenital diaphragmatic hernia (\%) & $9(42.9)$ & $1(6.7)$ & \\
\hline Non-CDH-related pulmonary hypoplasia (\%) & $3(14.3)$ & $1(6.7)$ & \\
\hline Meconium aspiration syndrome $(\%)$ & $4(19)$ & $8(53.3)$ & \\
\hline Infectious etiologies $(\%)$ & $1(4.8)$ & $4(26.7)$ & \\
\hline Idiopathic PPHN & 0 & $1(6.7)$ & \\
\hline Other $^{\mathrm{a}}$ & $4(17.2)$ & 0 & \\
\hline \multicolumn{4}{|l|}{ Adverse effects from epoprostenol } \\
\hline Need for fluid boluses post-initiation (\%) & $16(76.2)$ & $5(33.3)$ & 0.017 \\
\hline $\begin{array}{l}\text { Volume of fluid boluses in first } 24 \mathrm{~h} \text { (median } \mathrm{ml} / \mathrm{kg} \text { / } \\
\text { day, IQR) }\end{array}$ & $49(15,63)$ & $10(9,23)$ & 0.31 \\
\hline Hypotension requiring stopping of epoprostenol (\%) & $6(28.6)$ & $2(13.3)$ & 0.42 \\
\hline Severe flushing $(\%)$ & 0 & 0 & - \\
\hline Diarrhea $(\%)$ & 0 & 0 & - \\
\hline Severe tachycardia $(\%)$ & 0 & $1(6.7)$ & 1 \\
\hline Severe bradycardia $(\%)$ & 0 & 0 & - \\
\hline \multicolumn{4}{|l|}{ Feedings $^{b}$} \\
\hline Age at first enteral feeds (median days, IQR) & $17(14,23)$ & $12(7,24)$ & 0.42 \\
\hline $\begin{array}{l}\text { Age at } 100 \mathrm{ml} / \mathrm{kg} / \text { day of enteral feeds (median days, } \\
\text { IQR) }\end{array}$ & $26(22,39)$ & $19(13,33)$ & 0.33 \\
\hline Age at full PO feeds (median days, IQR) & $55(28,99)$ & $34(21,51)$ & 1 \\
\hline G-tube $(\%)$ & $1(14.3)$ & $1(6.7)$ & 0.63 \\
\hline Intraventricular hemorrhage & $3(42.9)$ & $1(6.7)$ & 0.09 \\
\hline Discharge respiratory disposition & & & 0.001 \\
\hline Died & $14(66.7)$ & 0 & \\
\hline No support & $5(23.8)$ & $11(73.3)$ & \\
\hline Nasal cannula & $1(4.8)$ & $3(20)$ & \\
\hline Tracheostomy & $1(4.8)$ & 0 & \\
\hline Unknown & 0 & $1(6.7)$ & \\
\hline
\end{tabular}

${ }^{a}$ Other diagnoses for non-responders (4): alveolar capillary dysplasia, severe respiratory distress syndrome, Beckwith-Weidemann syndrome with ompalocele, premature ductus arterosis closure secondary to maternal indomethacin exposure

${ }^{\mathrm{b}}$ Survivors only, $n=7$ for Epoprostenol non-responders use of milrinone for iNO-resistant PPHN [29] but the only active trial is restricted to patients with congenital diaphragmatic hernia [30].

Some studies have utilized epoprostenol doses significantly higher than we report. This may be due to our use of milrinone, which has been reported to potentiate the beneficial effects of prostacyclin in the treatment of pulmonary hypertension. This has plausibility as both medications exert their action through the same intracellular intermediary, cAMP, but through different mechanisms. Whereas prostacyclin or prostacyclin analogs such as epoprostenol increase cAMP levels via activation of adenylate cyclase, milrinone increases cAMP levels by inhibiting metabolism via phosphodiesterase-3. Data are limited mostly to animal models of pulmonary hypertension utilizing ex vivo approaches [31] or treatment of animals with inhaled prostacyclin rather than IV epoprostenol [32-34]. Consistent with pre-clinical data, limited patient data find a synergistic effect between inhaled prostacyclin and milrinone $[35,36]$. We are unaware of data examining the combined effects of IV epoprostenol and IV milrinone in children or adults with pulmonary hypertension. However, it may be reasonable to surmise that IV epoprostenol also has beneficial effects in combination with IV milrinone. It is also possible that the synergistic effects of milrinone noted in pre-clinical data may explain the observed beneficial epoprostenol effects at lower doses than previously utilized and thus avoid higher doses with the risk of dose-related adverse effects. In contrast, a prior case series [8] used a starting epoprostenol dose of $20 \mathrm{ng} / \mathrm{kg} / \mathrm{min}$ with median doses of 50 
Table 4 Changes in oxygenation index after initiation of epoprostenol
OI comparison between groups at 4-h intervals after epoprostenol initiation

\begin{tabular}{llll}
\hline & Non-responders $^{\mathrm{a}}$ & Responders $^{\mathrm{b}}$ & $p$-Value \\
\hline OI baseline (median, IRQ) & $41.8(31,51.7)$ & $35.6(29.5,55.5)$ & 0.409 \\
OI 4 h (median, IRQ) & $42.3(30.7,59.5)$ & $23.1(13,32.2)$ & 0.002 \\
OI 8 h (median, IRQ) & $29.3(21.7,59.2)$ & $14.3(10,27.5)$ & 0.041 \\
OI 12 h (median, IRQ) & $32.2(26.8,38.6)$ & $18.7(9.6,24.5)$ & 0.014 \\
OI 16 h (median, IRQ) & $26.9(26.2,34.3)$ & $15.3(9.6,23.5)$ & 0.051 \\
OI 20 h (median, IRQ) & $33.6(27,35.9)$ & $20.3(16.5,26.5)$ & 0.007 \\
OI 24 h (median, IRQ) & $32.1(12.3,39.2)$ & $18.1(16.6,23.8)$ & 0.077
\end{tabular}

OI differences between paired patients at baseline and later time points ${ }^{\mathrm{c}}$

\begin{tabular}{lllll} 
& $\begin{array}{l}\text { Non-responders } \\
\text { Median change }\end{array}$ & $\boldsymbol{p}$-Value & $\begin{array}{l}\text { Responders } \\
\text { Median change }\end{array}$ & $\boldsymbol{p}$-Value \\
Baseline to $4 \mathrm{~h}$ & 9.5 & 0.62 & -9.05 & 0.017 \\
Baseline to $8 \mathrm{~h}$ & -7.6 & 0.152 & -11.6 & 0.003 \\
Baseline to $12 \mathrm{~h}$ & -5.7 & 0.285 & -11.5 & 0.008 \\
Baseline to $16 \mathrm{~h}$ & -10.2 & 0.131 & -16.5 & 0.003 \\
Baseline to $20 \mathrm{~h}$ & -1.9 & 0.314 & -16.4 & 0.008 \\
Baseline to $24 \mathrm{~h}$ & -6.8 & 0.424 & -13.3 & 0.002 \\
\hline
\end{tabular}

${ }^{\mathrm{a}}$ Total $n$ is 21 patients. At individual time points-21, 17, 13, 10, 11, 9, and 7 at baseline, 4, 8, 12, 16, 20, and $24 \mathrm{~h}$

${ }^{\mathrm{b}}$ Total $n$ is 15 patients. At individual time points-15, 14, 15, 15, 14, 12, and 15 at baseline, 4, 8, 12, 16, 20, and $24 \mathrm{~h}$

${ }^{c}$ Median change and $p$-values are reflective of only those patients with available data at both time points $\mathrm{ng} / \mathrm{kg} / \mathrm{min}$ reached. Notable management differences in that series are the use of conventional mechanical ventilation and the lack of concomitant milrinone use.

For many years, a significant concern regarding IV epoprostenol use has been adverse effects. Unlike iNO which exerts local effects to only aerated lung segments, epoprostenol is a non-specific vasodilator with the tendency to cause unwanted systemic vasodilation leading some patients to experience dose-limiting hypotension. Hypotension has been a primary reason for many to avoid its use in neonates and consider inhaled epoprostenol or other approaches instead. As expected, we did find signs of systemic vasodilation in this cohort. After initiation of epoprostenol, non-responders had a greater need for volume resuscitation, but we found no statistically significant difference between groups in hypotension requiring cessation of epoprostenol infusion.

Although our center utilizes IV epoprostenol exclusively, most reported cases of neonatal epoprostenol therapy have utilized inhaled epoprostenol. Inhaled epoprostenol is delivered by aerosolizing the available IV formulation [5]. Similar to the IV formulation, nebulized epoprostenol has a short half-life and requires continuous therapy. Potential advantages of nebulized epoprostenol include less systemic effects and improved ventilation-perfusion matching. Potential complicating factors include limitations in delivery systems, accuracy in dose delivery, and irritant effects on the airway [5]. The data regarding nebulized epoprostenol efficacy have been limited with small patient numbers and one study which reported hypotension in 5 of 13 neonates, despite the inhaled route [10-12].

The strengths of this work include the increased number of patients we studied who were treated with IV epoprostenol compared to prior reports and detailed post-initiation data regarding OI changes, adverse effects, and medication dosing. Our restriction to only those patients already unresponsive to maximal pre-ECMO pulmonary hypertension management may lead one to give consideration to an epoprostenol trial prior to initiation of ECMO if further supporting evidence emerges.

The greatest limitations of our work are the retrospective nature of our data collection and the lack of a contemporary control group or randomized clinical trial. Additionally, although general epoprostenol dosing strategies were adhered to by our clinicians, a strict management protocol did not exist. We therefore cannot rule out a selection bias for initiating epoprostenol therapy. As a result, we chose to group our patients based on clinical outcome and compared a group that eventually required ECMO or died (nonresponders) to all others (responders). Further, it is possible that the responder group, comprised largely of patients with meconium aspiration syndrome and infectious etiologies, may have improved irrespective of epoprostenol exposure. However, the epoprostenol responder group had statistically 
and clinically significant improvements within $4 \mathrm{~h}$ of epoprostenol initiation in a window when many patients would have been placed on ECMO. The lack of a control group significantly limited our ability to determine safety beyond short-term adverse effects. Lastly, 95\% of our patients were receiving IV milrinone therapy prior to epoprostenol initiation as this is part of our sequential management approach. This may limit the generalizability of our findings for those centers that do not use milrinone as part of their management approach for severe PPHN.

In conclusion, we provide data demonstrating apparent efficacy of IV epoprostenol in patients with iNO-refractory PPHN, with improvement most notable in patients with meconium aspiration syndrome and infectious etiologies. A clinically significant response in comparison to nonresponders was seen within $4 \mathrm{~h}$ of initiation and sustained through $24 \mathrm{~h}$. Epoprostenol-responsive patients uncommonly experienced adverse effects that required a cessation of the medication, making this an attractive therapeutic option for further investigation. Based on our data, future epoprostenol clinical trials for iNO-refractory PPHN would best focus on patients without underlying pulmonary hypoplasia. A blinded randomized controlled trial is needed to better define the role of epoprostenol in treatment of iNOrefractory PPHN.

Acknowledgements We thank Brenda Stanley, Stephanie Mahan, Katy Kohlleppel, and Drs. Maria Pierce; Sanjuanita Garza-Cox and Cheryl Motta for their contributions towards data collection and entry. We thank Drs. Reese Clark, Brad Yoder, and Matthew Egalka for their critical feedback on this manuscript.

\section{Compliance with ethical standards}

Conflict of interest The authors declare that they have no conflict of interest.

\section{References}

1. Walsh-Sukys MC, Tyson JE, Wright LL, Bauer CR, Korones SB, Stevenson DK, et al. Persistent pulmonary hypertension of the newborn in the era before nitric oxide: practice variation and outcomes. Pediatrics. 2000;105:14-20.

2. Lakshminrusimha S, Konduri GG, Steinhorn RH. Considerations in the management of hypoxemic respiratory failure and persistent pulmonary hypertension in term and late preterm neonates. $\mathbf{J}$ Perinatol. 2016;36(Suppl 2):S12-9.

3. Steinhorn RH. Pharmacotherapy for pulmonary hypertension. Pediatr Clin North Am. 2012;59:1129-46.

4. Konduri GG, Solimano A, Sokol GM, Singer J, Ehrenkranz RA, Singhal N, et al. A randomized trial of early versus standard inhaled nitric oxide therapy in term and near-term newborn infants with hypoxic respiratory failure. Pediatrics. 2004;113:559-64.

5. Hill NS, Preston IR, Roberts KE. Inhaled therapies for pulmonary hypertension. Respir Care. 2015;60:794-802.

6. Cassin S, Tod ML, Frisinger JE, Jordan JA, Philips JB. Use of prostacyclin in persistent fetal circulation. Lancet. 1979;2:638.
7. Parker TA, Ivy DD, Kinsella JP, Torielli F, Ruyle SZ, Thilo EH, et al. Combined therapy with inhaled nitric oxide and intravenous prostacyclin in an infant with alveolar-capillary dysplasia. Am J Respir Crit Care Med. 1997;155:743-6.

8. Eronen M, Pohjavuori M, Andersson S, Pesonen E, Raivio KO. Prostacyclin treatment for persistent pulmonary hypertension of the newborn. Pediatr Cardiol. 1997;18:3-7.

9. Kelly LK, Porta NFM, Goodman DM, Carroll CL, Steinhorn RH. Inhaled prostacyclin for term infants with persistent pulmonary hypertension refractory to inhaled nitric oxide. J Pediatr. 2002;141:830-2.

10. Brown AT, Gillespie JV, Miquel-Verges F, Holmes K, Ravekes W, Spevak P, et al. Inhaled epoprostenol therapy for pulmonary hypertension: improves oxygenation index more consistently in neonates than in older children. Pulm Circ. 2012;2:61-6.

11. Bindl L, Fahnenstich H, Peukert U. Aerosolised prostacyclin for pulmonary hypertension in neonates. Arch Dis Child Fetal Neonatal Ed. 1994;71:F214-6.

12. Soditt V, Aring C, Groneck P. Improvement of oxygenation induced by aerosolized prostacyclin in a preterm infant with persistent pulmonary hypertension of the newborn. Intensive Care Med. 1997;23:1275-8.

13. Bush A, Busst CM, Knight WB, Shinebourne EA. Comparison of the haemodynamic effects of epoprostenol (prostacyclin) and tolazoline. Br Heart J. 1988;60:141-8.

14. Bush A, Busst C, Booth K, Knight WB, Shinebourne EA. Does prostacyclin enhance the selective pulmonary vasodilator effect of oxygen in children with congenital heart disease? Circulation. 1986;74:135-44.

15. Turanlahti MI, Laitinen PO, Sarna SJ, Pesonen E. Nitric oxide, oxygen, and prostacyclin in children with pulmonary hypertension. Heart. 1998;79:169-74.

16. Barst RJ, Maislin G, Fishman AP. Vasodilator therapy for primary pulmonary hypertension in children. Circulation. 1999;99:1197-208.

17. Yung D, Widlitz AC, Rosenzweig EB, Kerstein D, Maislin G, Barst RJ. Outcomes in children with idiopathic pulmonary arterial hypertension. Circulation. 2004;110:660-5.

18. Nakayama T, Shimada H, Takatsuki S, Hoshida H, Ishikita T, Matsuura $\mathrm{H}$, et al. Efficacy and limitations of continuous intravenous epoprostenol therapy for idiopathic pulmonary arterial hypertension in Japanese children. Circ J. 2007;71:1785-90.

19. Lammers AE, Hislop AA, Flynn Y, Haworth SG. Epoprostenol treatment in children with severe pulmonary hypertension. Heart. 2007;93:739-43.

20. Fraisse A, Jais X, Schleich J-M, di Filippo S, Maragnès P, Beghetti M, et al. Characteristics and prospective 2-year follow-up of children with pulmonary arterial hypertension in France. Arch Cardiovasc Dis. 2010;103:66-74.

21. van Loon RLE, Roofthooft MTR, Delhaas T, van Osch-Gevers M, Harkel ten ADJ, Strengers JLM, et al. Outcome of pediatric patients with pulmonary arterial hypertension in the era of new medical therapies. Am J Cardiol. 2010;106:117-24.

22. Skarda DE, Yoder BA, Anstadt EE, Lally PA, Greene T, McFadden M, et al. Epoprostenol does not affect mortality in neonates with congenital diaphragmatic hernia. Eur J Pediatr Surg. 2015;25:454-9.

23. Nakwan N, Chaiwiriyawong P. An international survey on persistent pulmonary hypertension of the newborn: a need for an evidence-based management. J Neonatal Perinat Med. 2016;9:243-50.

24. Shivananda S, Ahliwahlia L, Kluckow M, Luc J, Jankov R, McNamara P. Variation in the management of persistent pulmonary hypertension of the newborn: a survey of physicians in Canada, Australia, and New Zealand. Am J Perinatol. 2012;29:519-26. 
25. Bassler D, Choong K, McNamara P, Kirpalani H. Neonatal persistent pulmonary hypertension treated with milrinone: four case reports. Biol Neonate. 2006;89:1-5.

26. McNamara PJ, Shivananda SP, Sahni M, Freeman D, Taddio A. Pharmacology of milrinone in neonates with persistent pulmonary hypertension of the newborn and suboptimal response to inhaled nitric oxide. Pediatr Crit Care Med. 2013;14:74-84.

27. Deb B, Bradford K, Pearl RG. Additive effects of inhaled nitric oxide and intravenous milrinone in experimental pulmonary hypertension. Crit Care Med. 2000;28:795-9.

28. McNamara PJ, Laique F, Muang-In S, Whyte HE. Milrinone improves oxygenation in neonates with severe persistent pulmonary hypertension of the newborn. J Crit Care. 2006;21:217-22.

29. Lakshminrusimha $\mathrm{S}$, Steinhorn RH. Inodilators in nitric oxide resistant persistent pulmonary hypertension of the newborn. Pediatr Crit Care Med. 2013;14:107-9.

30. Milrinone in Congenital Diaphragmatic Hernia. Full Text View. ClinicalTrials.gov. https://clinicaltrials.gov/ct2/show/NCT02951130.

31. Lakshminrusimha S, Porta NFM, Farrow KN, Chen B, Gugino $\mathrm{SF}$, Kumar $\mathrm{VH}$, et al. Milrinone enhances relaxation to prostacyclin and iloprost in pulmonary arteries isolated from lambs with persistent pulmonary hypertension of the newborn. Pediatr Crit Care Med. 2009;10:106-12.
32. Schermuly RT, Ghofrani HA, Enke B, Weissmann N, Grimminger F, Seeger W, et al. Low-dose systemic phosphodiesterase inhibitors amplify the pulmonary vasodilatory response to inhaled prostacyclin in experimental pulmonary hypertension. Am J Respir Crit Care Med. 1999;160:1500-6.

33. Rashid N, Morin FC, Swartz DD, Ryan RM, Wynn KA, Wang H, et al. Effects of prostacyclin and milrinone on pulmonary hemodynamics in newborn lambs with persistent pulmonary hypertension induced by ductal ligation. Pediatr Res. 2006;60:624-9.

34. Kumar VH, Swartz DD, Rashid N, Lakshminrusimha S, Ma C, Ryan RM, et al. Prostacyclin and milrinone by aerosolization improve pulmonary hemodynamics in newborn lambs with experimental pulmonary hypertension. J Appl Physiol. 2010;109:677-84.

35. Laflamme M, Perrault LP, Carrier M, Elmi-Sarabi M, Fortier A, Denault AY. Preliminary experience with combined inhaled milrinone and prostacyclin in cardiac surgical patients with pulmonary hypertension. J Cardiothorac Vasc Anesth. 2015;29:38-45.

36. Haraldsson sA, Kieler-Jensen N, Ricksten SE. The additive pulmonary vasodilatory effects of inhaled prostacyclin and inhaled milrinone in postcardiac surgical patients with pulmonary hypertension. Anesth Analg. 2001;93:1439-45. Table of contents 